\title{
Are streamflow recession characteristics really characteristic?
}

\author{
M. Stoelzle, K. Stahl, and M. Weiler \\ Chair of Hydrology, University of Freiburg, Freiburg, Germany \\ Correspondence to: M. Stoelzle (michael.stoelzle@hydrology.uni-freiburg.de)
}

Received: 6 September 2012 - Published in Hydrol. Earth Syst. Sci. Discuss.: 19 September 2012

Revised: 16 January 2013 - Accepted: 4 February 2013 - Published: 27 February 2013

\begin{abstract}
Streamflow recession has been investigated by a variety of methods, often involving the fit of a model to empirical recession plots to parameterize a non-linear storageoutflow relationship based on the $\mathrm{d} Q / \mathrm{d} t-Q$ method. Such recession analysis methods (RAMs) are used to estimate hydraulic conductivity, storage capacity, or aquifer thickness and to model streamflow recession curves for regionalization and prediction at the catchment scale. Numerous RAMs have been published, but little is known about how comparably the resulting recession models distinguish characteristic catchment behavior. In this study we combined three established recession extraction methods with three different parameter-fitting methods to the power-law storage-outflow model to compare the range of recession characteristics that result from the application of these different RAMs. Resulting recession characteristics including recession time and corresponding storage depletion were evaluated for 20 mesoscale catchments in Germany. We found plausible ranges for model parameterization; however, calculated recession characteristics varied over two orders of magnitude. While recession characteristics of the 20 catchments derived with the different methods correlate strongly, particularly for the RAMs that use the same extraction method, not all rank the catchments consistently, and the differences among some of the methods are larger than among the catchments. To elucidate this variability we discuss the ambiguous roles of recession extraction procedures and the parameterization of the storage-outflow model and the limitations of the presented recession plots. The results suggest strong limitations to the comparability of recession characteristics derived with different methods, not only in the model parameters but also in the relative characterization of different catchments. A multiple-methods approach to investigating streamflow recession characteristics should be considered for applications whenever possible.
\end{abstract}

\section{Introduction}

Recession analysis methods (RAMs) are widely used to investigate the storage-outflow relationship of catchments. As in rainless periods streamflow originates solely from stored water in a catchment (aquifers, soils, lakes, etc.), the shapes of these recession curves should be characteristic for a specific catchment. If this is the case, then they could be used for low-flow prediction and estimation of total dynamic storage. Generally, low flow at the catchment scale is examined with baseflow separation techniques, low-flow frequency analysis, low-flow indices and recession analysis methods, which have been comprehensively reviewed by Hall (1968), Tallaksen (1995), Smakhtin (2001) and Dewandel et al. (2003). Recession analysis methods have a long tradition (cf. Ding, 1966, 1974; Hall, 1968; Brutsaert and Nieber, 1977); hence today many established methods can be used. However, there are large differences in these methods that often employ subjective or somehow imprecise graphical approaches (e.g. master recession curves, matching strip, recursive filters, dependence on a certain recession starting point with variable initial catchment conditions, etc.). For instance, Anderson and Burt (1980) have shown that graphical plotting techniques can lead to biased recession characteristics and even semi-logarithmic plotting is more appropriate to describe single recession events than a general storage-outflow behavior. To analyze streamflow recessions individually instead of collectively ignores the variability of storage depletion, which is represented by numerous recession events and not by one single event.

To overcome most of these restrictions, Brutsaert and Nieber (1977) presented a method to parameterize a powerlaw storage-outflow model based on the Boussinesq equation, which described flow from an unconfined aquifer into the adjoined stream (Hall, 1968). For that purpose the 
negative decline in discharge $(-\mathrm{d} Q / \mathrm{d} t)\left(\mathrm{mm} \mathrm{d}^{-2}\right)$ is plotted versus discharge $(Q)\left(\mathrm{mm} \mathrm{d}^{-1}\right)$ to eliminate time as a reference, hereafter referred to as "recession plots" following Kirchner (2009). This allows the analysis of catchmentspecific streamflow recessions collectively and the derivation of storage-outflow relationships correlated to aquifer hydraulic properties solely by the means of discharge $Q$ as a function of storage $S\left(\mathrm{~mm} \mathrm{~d}^{-1}\right)$. In absence of aquifer recharge or leakage and when precipitation $P\left(\mathrm{~mm} \mathrm{~d}^{-1}\right)$ and evapotranspiration $\left(\mathrm{mm} \mathrm{d}^{-1}\right)$ is negligible or very small compared to discharge $Q$ (Kirchner, 2009), the water balance equation can be used to relate change in storage $S$ directly to discharge $Q$ :

$$
\frac{\mathrm{d} S}{\mathrm{~d} t}=-Q
$$

Consequently a power-law relationship between $-\mathrm{d} Q / \mathrm{d} t$ and discharge $Q$,

$-\frac{\mathrm{d} Q}{\mathrm{~d} t}=a Q^{b}$

with factor $a\left[\mathrm{~L}^{(1-b)} \mathrm{T}^{(2-b)}\right]$ and exponent $b$ [-], allows for both linear $(b=1)$ and non-linear $(b \neq 1)$ storage-outflow relationships (Brutsaert and Nieber, 1977).

With that power-law relationship (Eq. 2) a variety of hydraulic aquifer properties can be represented and analyzed by recession plots. The plots are best shown on $\log -\log$ scale, because both $-\mathrm{d} Q / \mathrm{d} t$ and $Q$ typically span several orders of magnitude during recessions. However, a reliable and unique description of catchment-specific recession behavior is still challenging, because, first, a specific extraction procedure is required to obtain a characteristic recession plot and, second, a method to fit the power-law relationship to derive storageoutflow model parameters has to be chosen.

Rainfall data can be used to exclude improper streamflow recession during periods with precipitation. However, when local rainfall data are missing or seem to be imprecise the declining parts of hydrograph $(\mathrm{d} Q / \mathrm{d} t<0)$ can be used to identify streamflow recessions (Brutsaert, 2008; Palmroth et al., 2010). Early stages of these recessions are often excluded to avoid the influence of preceding storm and surface flow. Commonly at least the first 5 days of periods with declining streamflow are removed from analysis (e.g. Szilagyi and Parlange, 1998; Peña-Arancibia et al., 2010), but studies can also be found that eliminated an interval between 1 and 10 days (Zecharias and Brutsaert, 1988a; Vogel and Kroll, 1992; Parlange et al., 2001; Malvicini et al., 2005; van Dijk, 2010; Wang and Cai, 2010). Singh and Stall (1971) divided the declining hydrograph at the inflection point and analyzed only the latter part to reduce influence of surface flows at the beginning of recession. Other studies have extended this restriction and used only recessions that started two days after the inflection point (Wittenberg and Sivapalan, 1999; Wang and Cai, 2010). Moreover a minimum recession length has also been established (Vogel and Kroll, 1992) to assure streamflow recessions are connected to pure storage depletion (longer recessions) rather than being influenced by surface or storm flow (shorter recessions). The threshold for this minimum length has varied widely in published extraction procedures from 2 days (e.g. Mendoza et al., 2003) up to 10 days (e.g. Vogel and Kroll, 1992), and it is often an issue of available streamflow recession data and regional hydrological and climatological properties.

Variation of storage-outflow model parameterization results from different parameter-fitting methods to the recession plots. Although the non-linear, power-law relationship can be expressed as a linear model in log-scaled recession plots, one has to decide in which way parameters $a$ and $b$ should be fitted to recession data. With a linear storageoutflow model $(b=1)$, recession analysis methods might be better comparable among each other, but a fixed slope may not represent dynamic catchment behavior over a wide range of recession flows (Tallaksen, 1995). However, Wittenberg (1999) concluded that a fixed $b=1.5$ seems to be a standard power exponent for unconfined aquifers, and Wittenberg and Sivapalan (1999) suggested that this assumption is more physically realistic than a linear storage-outflow relationship. Brutsaert and Nieber (1977) argued that lower envelopes (with fixed slopes $b=1,1.5$ and 3 ) would represent the smallest $-\mathrm{d} Q / \mathrm{d} t$ for a certain $Q$ and are therefore a characterization of a non-linear and catchment-specific storage depletion from aquifers. One should note that evapotranspiration may cause faster streamflow recession (Federer, 1973) and a lower envelope will represent a more resilient storageoutflow relationship, whereas an upper envelope with a maximum observable rate of streamflow decline (Zecharias and Brutsaert, 1988a; Wang, 2011) will estimate faster recessions, e.g. due to evapotranspiration from groundwater.

Apart from envelopes numerous studies have implemented a linear model fitting obtained by least square fit through all recession data or binned means in order to focus more on the average recession behavior of catchments (Vogel and Kroll, 1992; Kirchner, 2009; Krakauer and Temimi, 2011). Fitting a linear regression through all data points in a recession plot gives the same weight to all $-\mathrm{d} Q / \mathrm{d} t$ values for a certain $Q$. Alternatively, a "binning" procedure that divides recession plots into different segments by splitting the range of log$Q$ into several parts has been employed (Kirchner, 2009). For each part (bin) averaged values of $-\mathrm{d} Q / \mathrm{d} t$ and $Q$ can be calculated separately, thus leading to a partitioning of recession behavior according to certain streamflow rates. The mean values of $-\mathrm{d} Q / \mathrm{d} t$ and $Q$ of a variable amount of bins can then be used to fit the linear model. For example, binning was used by Parlange et al. (2001) to illustrate a bias in parameterization due to method-specific model fitting. Palmroth et al. (2010) presented an approach to combine lower envelope and binning by the means of a boundary line analysis adopted from Schäfer et al. (2000). The authors calculated a slightly upshifted "lower" envelope to obtain a relationship 
between $-\mathrm{d} Q / \mathrm{d} t$ and $Q$, which is not influenced by the lowest $-\mathrm{d} Q / \mathrm{d} t$ values in the recession plot. Those lowest values of $-\mathrm{d} Q / \mathrm{d} t$ could be influenced by streamflow measurement precision. A scatter in recession plots might be produced by multiples of the minimum rate of $-\mathrm{d} Q / \mathrm{d} t$ (Rupp and Selker, 2006a), especially in the case of low streamflow. Consequently Kirchner (2009) used binned means and standard errors for $-\mathrm{d} Q / \mathrm{d} t$ and $Q$ to fit an empirical function weighted by the reciprocal of the squared standard errors and to reduce the influence by highly uncertain data points. This procedure has been applied since then for different purposes (i.e. Krakauer and Temimi, 2011; Staudinger et al., 2011; Ajami et al., 2011).

Apart from the variety of adaptations of the original method by Brutsaert and Nieber (1977), these different RAMs have also been applied to various catchment types with different catchment areas and different physiographic, geological, and climatic characteristics including in humid (Troch et al., 1993), in tropical (Peña-Arancibia et al., 2010), in semi-arid (Mendoza et al., 2003; Ajami et al., 2011) and sub-artic (Lyon et al., 2009) regions. Furthermore methods have been applied to catchments with different land use characteristics such as forested catchments (Parlange et al., 2001), deforested catchments (Malvicini et al., 2005), mountainous catchments (Zecharias and Brutsaert, 1988a; Teuling et al., 2010) and also explicitly to small catchments (Krakauer and Temimi, 2011) and to a lowland plain with a deep aquifer (Rupp et al., 2009). The variety of applicability can also be seen in studies which estimated hydraulic conductivity (Troch et al., 1993), mountain block recharge (Ajami et al., 2011), catchment-scale evapotranspiration (Szilagyi et al., 2007; Palmroth et al., 2010) or permafrost thawing rates (Lyon et al., 2009). Other authors have detected trends in groundwater storage (Brutsaert and Sugita, 2008) or quantified human influences on low flows (Wang and Cai, 2009). Kirchner (2009) demonstrated that with a recession analysis method the preceding precipitation amount is quantifiable.

All these studies used slightly different adaptations of the original recession analysis method proposed by Brutsaert and Nieber (1977) and assumed that the recession characteristics obtained and used are specific to the catchment and its properties. A considerable number of studies have shown that streamflow recession characteristics could be related to catchment properties (see Price, 2011, for recent review), but regional generalizations of this relationship are still challenging (e.g. Gottschalk et al., 1997; Smakhtin, 2001; Krakauer and Temimi, 2011). Often only one recession analysis method was applied or the sensitivity of modified analysis methods was tested only in one catchment. More often streamflow recession analysis methods are adjusted for a specific case of application or a distinct set of catchments. However, when storage-outflow behavior is solely analyzed with streamflow data, multiple-methods approaches have been suggested to overcome potential biases of a single recession analysis method (Halford and Mayer, 2000).

Based on these experiences we ask the question, how will characteristic streamflow recessions derived by a single recession analysis method with specific assumptions and simplifications be within the pool of available methods? If streamflow recession characteristics are characteristic to the catchment rather than to the method used to derive them, then for a given set of catchments with different physical properties these characteristics (derived with different methods) should at least vary consistently (and thus characteristically) among the catchments. Ideally, the variability of recession characteristics among diverse catchments should be larger than the variability among different RAMs. To our knowledge, no systematic comparison of different recession analysis methods has investigated this question, and approaches to quantify the consistency among recession analysis methods are still missing. In this study we combined three established recession extraction methods with three different parameterfitting methods to the power-law storage-outflow model. The objectives of our study are:

1. to compare the range of recession characteristics that result from the application of these different recession analysis methods,

2. to elucidate the relative roles of extraction procedures and parameterization method for the storage-outflow model on the recession characteristics and

3. to test the effect of applying different recession analysis methods to distinguish recession characteristics of a regional set of streamflow records.

\section{Methods}

To ensure comparability of the recession analysis methods, we followed Brutsaert and Nieber (1977) to pair streamflow $Q=\left(Q_{t-1}+Q\right) / 2$ and streamflow recession rates $\mathrm{d} Q / \mathrm{d} t=Q_{t-1}-Q$ consistently. We then implemented three established recession analysis procedures: the Vogel method (Vogel and Kroll, 1992), the Brutsaert method (Brutsaert, 2008) and the Kirchner method (Kirchner, 2009). Each consists of a specific extraction procedure and a specific parameter fitting: herein called "linear regression", "lower envelopes" and "binning", respectively. Hence, the combination of extraction procedures and model parameterization lead to nine specific recession analysis methods (RAMs), whereas originally the Vogel method uses a linear regression, the Brutsaert method a lower envelope and the Kirchner method the binning procedure for model parameterization.

\subsection{Recession extraction}

The Vogel method selects recession segments from the decreasing parts of 3-day moving averages of streamflow. 
These segments must have a minimum length of 10 continuous days, and the decline in discharge for two consecutive data values has to be smaller than $30 \%$. Furthermore the first $30 \%$ of every recession segment is excluded to avoid the influence of storm and surface runoff at the beginning of streamflow recessions. The Brutsaert method omits nonrecession parts from hydrograph with a rule-based procedure. Data points within a recession segment have to comply with the following criteria: no values with positive or zero $\mathrm{d} Q / \mathrm{d} t$ are allowed and three data points after the last and two data points before the first positive or zero $\mathrm{d} Q / \mathrm{d} t$ are eliminated. Additionally a fourth data point is excluded after major events. Due to no further specification in this study a major event was defined as streamflow values greater than the $30 \%$ exceedance frequency $(Q 30)$ during the period of record. Further on, the Brutsaert method eliminates data points followed by values with a larger $-\mathrm{d} Q / \mathrm{d} t$ in order to exclude sudden anomalies and the ups and downs of $\mathrm{d} Q / \mathrm{d} t$ values during a recession. In contrast to these procedures the Kirchner method uses all pairs of streamflow data $Q$ and $\mathrm{d} Q / \mathrm{d} t$ during dry periods. Due to lack of precipitation and evapotranspiration data this method was adapted for data points with negative values of $\mathrm{d} Q / \mathrm{d} t$. A functional relationship between $-\mathrm{d} Q / \mathrm{d} t$ and $Q$ is determined based on ranges (bins) of $Q$, i.e. sorted averages of $-\mathrm{d} Q / \mathrm{d} t$ in certain ranges of $Q$. Working from the highest to the lowest values of logarithmic $Q$, bins with at least $1 \%$ of streamflow range are delimited to calculate the corresponding mean and standard error for $-\mathrm{d} Q / \mathrm{d} t$ and $Q$. Each bin then contains enough points that the half of mean $(-\mathrm{d} Q / \mathrm{d} t)$ is larger than its standard error. An overview of the main criteria of each recession extraction procedure can be found in Table 1 .

\subsection{Parameterization of storage-outflow model}

The power-law relationship between $-\mathrm{d} Q / \mathrm{d} t$ and streamflow $Q$ (Eq. 2) can be log-transformed to

$\log (-\mathrm{d} Q \mathrm{~d} t)=\log (a)+b \log (Q)$

to derive $\log (a)\left[\mathrm{L}^{(1-b)} \mathrm{T}^{(2-b)}\right]$ as intercept and $b[-]$ as slope of the best fit linear regression in place of a non-linear storage-outflow function (Brutsaert and Nieber, 1977; Wittenberg and Sivapalan, 1999). The Brutsaert method suggests a lower envelope to parameterize the recession model with $5 \%$ of the points below it, to take unavoidable errors into account. As the literature lacks the specific implementation details, in this study the model was fitted by means of a quantile regression (Koenker and Bassett Jr., 1978). The Vogel method instead uses a linear regression through all data points by ordinary least squares regression. Brutsaert and Lopez (1998) have shown that other fitting procedures (e.g. inverse least squares linear regression) lead to different estimations of slope $b$. However, as the scope of this paper aims at a comparison of the more fundamental differences of RAMs, we did not consider implementation of differ-

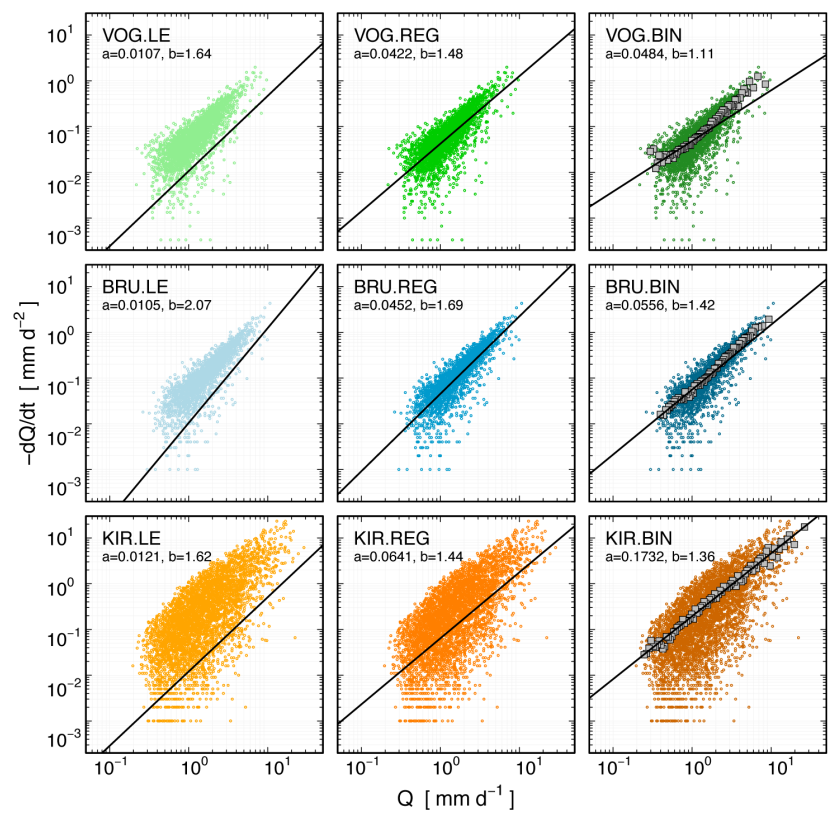

Fig. 1. Recession plots with intercepts $a$ and slopes $b$ for three extraction procedures (VOG, BRU, KIR) and three different fitted models (lower envelope, linear regression, binning). Daily streamflow data from the Kinzig catchment.

ent linear regression approaches. The Kirchner method fits a least squares regression through the binned means, weighted by the square of the standard error of each binned average (Kirchner, 2009). Due to the fact that this weighting is based on the previously calculated standard error of the binned means, we followed Krakauer and Temimi (2011), who have suggested a minimum data points' quantity in each bin. In order to calculate weights for each bin in each catchment, we have to define a minimum amount of binned data points $(n=6)$. Figure 1 illustrates an example of the applied RAMs and the different recession plots.

\subsection{Recession characteristics}

As a disjoint interpretation of the recession parameters $a$ and $b$ may be misleading, we computed two established recession characteristics to evaluate the impact of the parameterization on the prediction of streamflow recession. Recession time $T_{\mathrm{R}}(\mathrm{d})$ is defined as the time interval in which streamflow declined from median flow $(Q 50)$ to a low-flow threshold $(Q 90)$. Storage depletion $S_{\mathrm{R}}(\mathrm{mm})$ is the cumulative summation of streamflow solely related to storage-outflow. Starting with catchment-specific median flow $Q 50$ as initial streamflow, both recession characteristics were calculated as a general solution of Eq. (3) in respect to time $t$ with

$$
\begin{aligned}
& Q(t)=Q_{0} e^{-a t} \quad \text {, if } \quad b=1, \\
& Q(t)=\left(Q_{0}^{(1-b)}-[1-b] a t\right)^{\frac{1}{1-b}} \text {, if } \quad b \neq 1,
\end{aligned}
$$


Table 1. Main criteria to extract recessions from streamflow data.

\begin{tabular}{lllll}
\hline $\begin{array}{l}\text { Recession } \\
\text { extraction } \\
\text { procedure }\end{array}$ & Criterion & $\begin{array}{l}\text { Minimum } \\
\text { recession } \\
\text { length } \\
\text { [days] }\end{array}$ & $\begin{array}{l}\text { Excluding exterior } \\
\text { parts of recession } \\
\text { segment }\end{array}$ & $\begin{array}{l}\text { Excluding recession } \\
\text { segments depending } \\
\text { on anomalous } \\
\text { streamflow decline }\end{array}$ \\
\hline VOG & $\begin{array}{l}\text { Decreasing 3-day } \\
\text { moving average }\end{array}$ & 10 & first 30\% & $>30 \%$ \\
\hline BRU & $\mathrm{d} Q / \mathrm{d} t<0$ & $6-7^{*}$ & $\begin{array}{l}\text { first 3-4 days, } \\
\text { last 2 days }\end{array}$ & $\mathrm{d} Q\left(t_{i+1}\right) / \mathrm{d} t>\mathrm{d} Q\left(t_{i}\right) / \mathrm{d} t$ \\
\hline KIR & $\mathrm{d} Q / \mathrm{d} t<0$ & 1 & - & - \\
\hline
\end{tabular}

* Recessions have a minimum length of 6-7 days, because at least one "recession day" should remain after excluding non-recession parts.

whereas $a$ and $b$ are the fitted recession parameters (Szilagyi and Parlange, 1998). Note that in the first case with $b=1$ the storage-outflow model is an exponential decay function. $\mathrm{Nu}-$ merous comparable solutions for storage-outflow based on non-linear relationships between storage and discharge can be found in the literature (e.g. Brutsaert and Nieber, 1977; Wittenberg, 1999).

\subsection{Comparison among recession analysis methods (RAMs)}

The distribution of the nine different derived model parameters $a$ and $b$ and the recession characteristics $T_{\mathrm{R}}$ and $S_{\mathrm{R}}$ for the 20 streamflow records were assessed for similarities and differences. A Student's $t$ test was performed to test whether the mean $T_{\mathrm{R}}$ and mean $S_{\mathrm{R}}$ of two RAMs differ significantly from each other (with $95 \%$ confidence interval , $p<0.05$ ). The method-specific variability of $T_{\mathrm{R}}$ and $S_{\mathrm{R}}$ is evaluated with the help of boxplots spanning the interquartile range with whiskers extending to upper and lower $5 \%$ percentiles.

A Spearman rank correlation coefficient (Spearman's rho) was calculated between the $T_{R}$ and $\mathrm{S}_{\mathrm{R}}$ of all pairs of catchments derived with all RAMs. If the predicted $T_{\mathrm{R}}$ und $S_{\mathrm{R}}$ are really characteristic for a catchment, the different recession analysis methods should rank the catchments similarly with respect to these predictions. Spearman's rho of 1 reveals the same order of all catchments, a coefficient of -1 the completely opposite order.

Besides the analysis of rank correlation, we calculated the regression coefficient among all RAM results. For example, a regression coefficient of 1 indicates not only the same order but also the same estimations for predicted storage depletion by two different RAMs: a coefficient of 0.5 or 2 quantify that one RAM compared to another RAM leads to halved or doubled amount of storage depletion, respectively.

\section{Study sites and data}

We used daily streamflow data (1971-2009) of 20 mesoscale catchments (between $26 \mathrm{~km}^{2}$ and $954 \mathrm{~km}^{2}$ ) in the state of Baden-Württemberg in Germany (Fig. 2). Apart from catchment areas varying by two orders of magnitude, they also represent a wide range of physiographic and hydrogeological characteristics such as different geology (e.g. metamorphic, limestone, sandstone), drainage density $\left(0.2-1.8 \mathrm{~km} \mathrm{~km}^{-2}\right)$, mean slopes $(5-38 \%)$ or mean altitudes (226-850 $\mathrm{m}$ a.s.1.). The three common land covers are forests (20-92\%), pasture (2-36\%) and agriculture (0-66\%); urban areas within the catchments are negligible. All catchments can be classified as humid with annual precipitation ranging from $770 \mathrm{~mm}$ up to $1710 \mathrm{~mm}$. The hydrological regimes are mostly dominated by rain with some influence of snow resulting in a peak in spring and typically low flows in summer. However, both extremes can occur year round. Daily streamflow data in $\mathrm{m}^{3} \mathrm{~s}^{-1}$ (provided by the state of Baden Württemberg's Agency for the Environment, Measurement and Nature Conservation) were first converted to comparable unit area runoff $\left(\mathrm{mm} \mathrm{d}^{-1}\right)$. Streamflow in all catchments is near-natural with no known influence by dams, withdrawals or return flow. Three streamflow records have one missing value, one record has 18 and one record has 247 days with missing streamflow values, which were all excluded from the analysis.

\section{Results}

Combinations of 9 RAMs and streamflow data of 20 catchments led to 180 different recession model parameterizations. For simplification in the results section abbreviations are used for the different extraction procedures, VOG (Vogel's method), BRU (Brutsaert's method) and KIR (Kirchner's method), as well as for the three methods of model fitting, LE (lower envelope), REG (linear regression) and BIN (binning). 


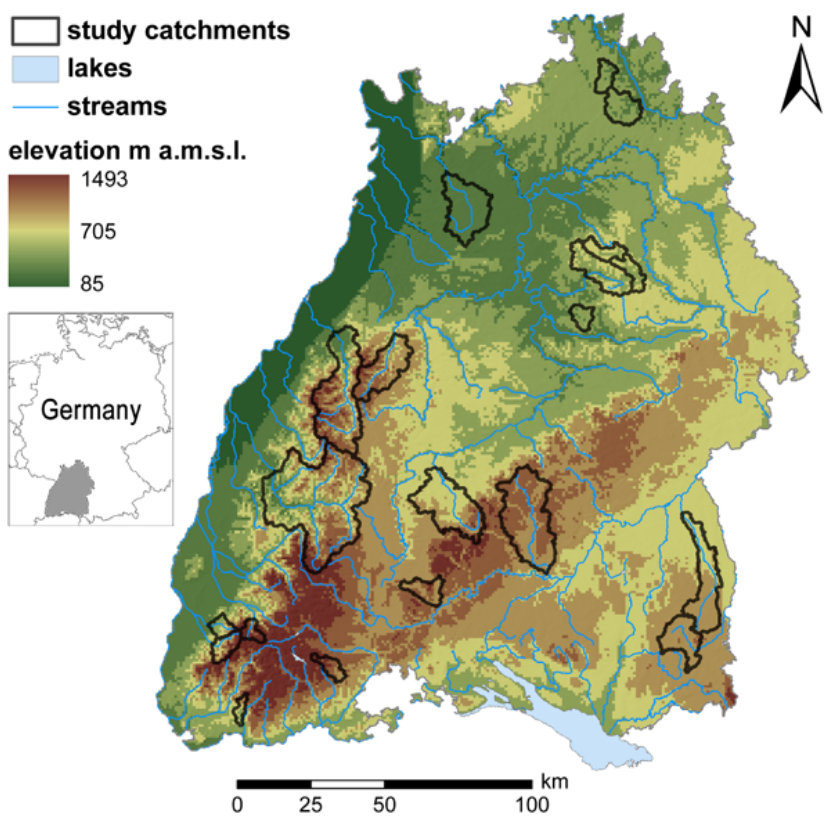

Fig. 2. Outlines and position of the 20 study catchments in BadenWürttemberg, Germany. Material from d-maps.com is used for the thumbnail map of Germany (http://d-maps.com/m/europa/germany/ allemagne/allemagne15.pdf).

Intercepts $a$ ranged (except for one outlier) from 0.001 up to $0.36 \mathrm{~mm}^{(1-b)} \mathrm{d}^{b}$ and slopes varied from 0.39 to 3.21 (Fig. 3a). We found a systematic order for parameters' medians within each extraction procedure. For intercept $a$ the order is $\mathrm{LE}<\mathrm{REG}<\mathrm{BIN}$, and for slope $b$ the order is LE $>$ REG $>$ BIN, except for KIR estimates. LE model fitting led to notably smaller values for intercept $a$ than all other methods; however, no clear pattern emerged for estimates of slope $b$.

We identified inverse patterns to $a$ in the results of recession time $T_{R}$ (Fig. 3b) and storage depletion $S_{R}$ (Fig. 3c). Values of $T_{\mathrm{R}}$ for all RAMs spanned two orders of magnitude from a few days up to almost one year. This can be shown in highly variable $T_{\mathrm{R}}$ for LE (62-342 days) with similar medians 105.5 days (VOG), 119.5 days (BRU) and 123.5 days (KIR) among the extraction procedures. However, REG and BIN model fitting with VOG and BRU extraction procedures led to shorter $T_{\mathrm{R}}$ of around three weeks (18.5 to 24.5 days), whereas KIR resulted in very quickly receding recessions with medians from 7 to 11 days. Accordingly to $T_{R}$, large $\mathrm{S}_{\mathrm{R}}$ was found for LE (up to $425 \mathrm{~mm}$ ) as well as smaller values especially for KIR.BIN down to almost $1 \mathrm{~mm}$ (Fig. 3c). Generally, LE generated approximately six-fold longer recession times and larger storage depletions than the other model-fitting methods. It also can be shown that apart from LE model fitting KIR led to slightly shorter recession times $T_{\mathrm{R}}$; thus, also smaller storage depletions $S_{\mathrm{R}}$ were found.

The t-test (values not presented) identified two groups with a significantly similar mean $S_{R}(p \leq 0.05)$. The first
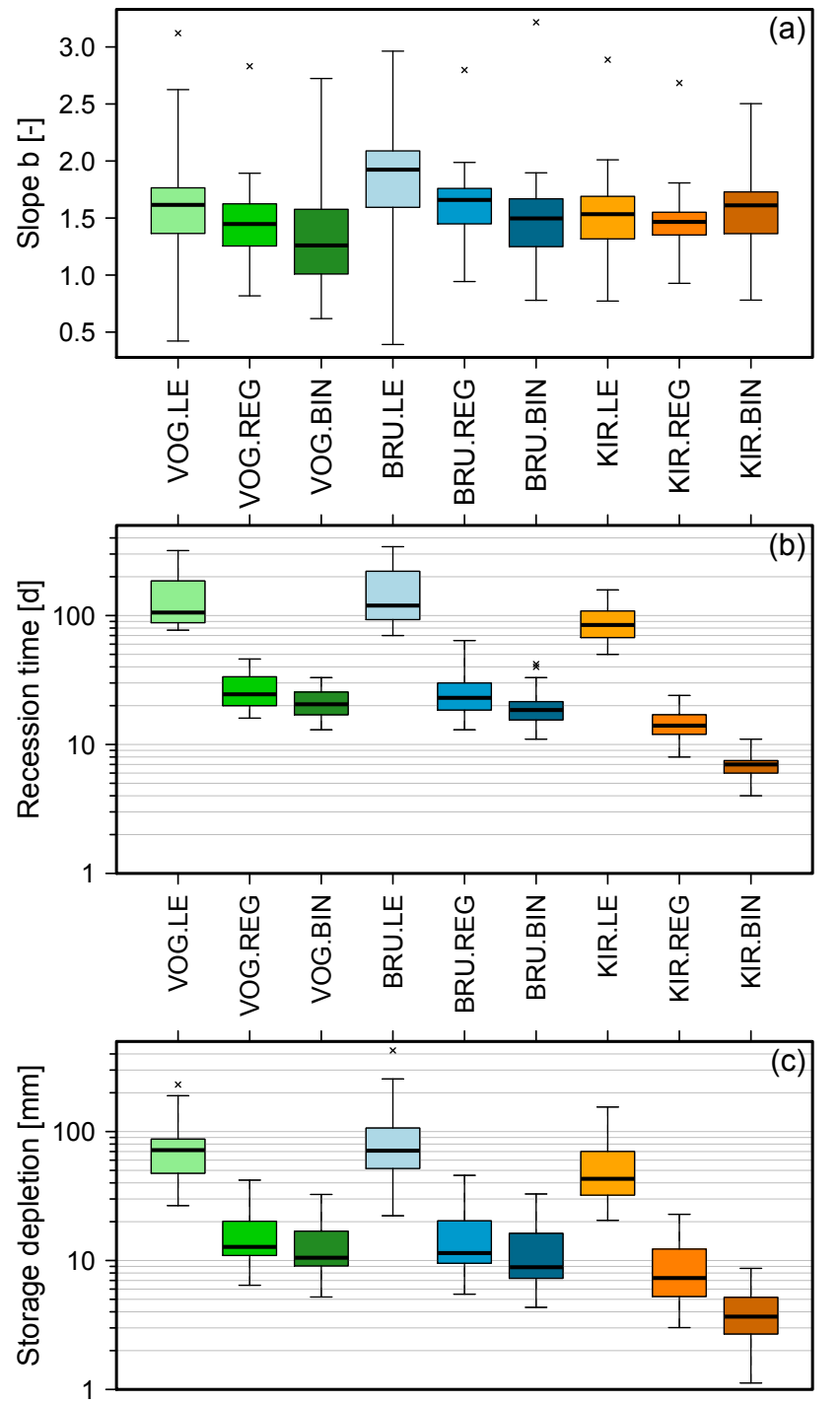

Fig. 3. Distributions of slope $b$ (a), recession time $T_{\mathrm{R}}$ (b) and storage depletion $S_{\mathrm{R}}$ (c) for the study catchments grouped by RAMs. The colored boxplots span the interquartile range; the whiskers extend according to the $R$-manual for the boxplot()-function to the most extreme data point, which is no more than three times the interquartile range from the box. Points that lie outside this range are marked as outlier (crosses).

group contains any particular combination of VOG.REG, VOG.BIN, BRU.REG and BRU.BIN $(n=6)$. The second group contains the RAMs with LE model fittings: VOG.LE, BRU.LE and KIR.LE $(n=3)$. These groups can also be seen in the boxplots for calculated storage depletion (Fig. 3c). The remaining 27 RAM combinations had statistically different means of $S_{\mathrm{R}}$.

In addition to the values, we distinguished the RAMs by how they order the calculated recession characteristics (e.g. storage depletion) of the 20 streamflow records. Spearman's rho $(\rho)$ values that compare the catchments' 


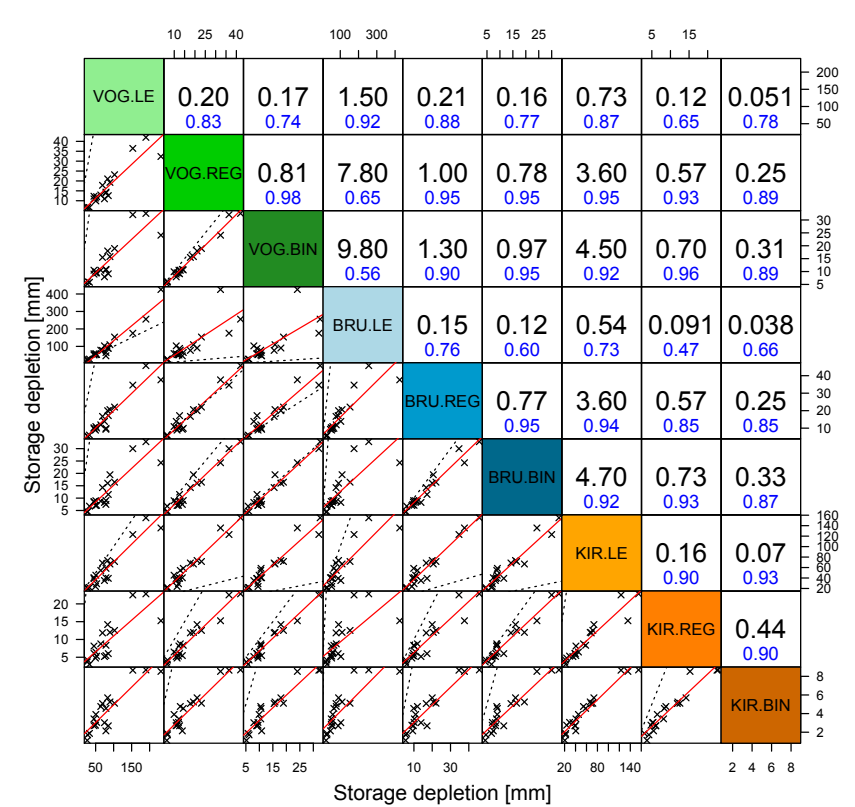

Fig. 4. Below diagonal: scatterplots for calculated storage depletion from each combination of RAMs with a linear regression (red line) and the $1: 1$ line (dashed line). Above diagonal: corresponding slope (black) and adjusted $R^{2}$ (blue) of the linear regression.

ranking according to the recession characteristics $T_{\mathrm{R}}$ and $S_{\mathrm{R}}$ are shown in Table 2. Spearman's rho for all pairs of RAMs ranged from 0.31 up to 0.91 for $T_{\mathrm{R}}$ and from 0.57 up to 0.96 for $S_{\mathrm{R}}$. Hereinafter we focus the analysis on $S_{\mathrm{R}}$, because the results for $T_{\mathrm{R}}$ are comparable. Values of $\rho$ show a positive correlation of the estimated characteristics between all pairs of RAMs. The most consistent ranking was found within each extraction procedure regardless of which model-fitting method was used. Mean Spearman's rho is highest within KIR (with mean $\bar{\rho}=0.92$ of all pairs from three model fittings), but ranking is also relatively consistent within BRU $(\bar{\rho}=0.88)$ and VOG $(\bar{\rho}=0.82)$. In contrast, ranking is less consistent within each model-fitting method (with lower $\bar{\rho}<0.82$ for all pairs with different extraction methods in an order of rank correlations of BIN $>$ REG $>$ LE). But, more importantly, we found weak to medium rank correlations $(\bar{\rho}=0.73)$ among the three originally published combinations of recession extraction and model fitting (Vogel method with linear regression, Brutsaert method with lower envelope, Kirchner method with binning).

The regression coefficient, i.e. the slope of a linear regression between recession characteristics estimated with two RAMs, can be used to further quantify the relationship between different RAMs (Fig. 4). The coefficient varied by two orders of magnitude for $S_{\mathrm{R}}$. Regression coefficients between 1.30 and 0.78 can be found between all combinations of VOG.REG, VOG.BIN, BRU.REG and BRU.BIN (mean $\left.R^{2}=0.94\right)$. The relationships between the three originally published methods were notably weaker (mean $R^{2}=0.73$ ).
Model fitting by linear regressions or binning combined with Kirchner's extraction method generally led to smaller $S_{R}$ in comparison to those estimated with all other RAMs (cf. maximal slope $=0.73$ in the columns KIR.REG and KIR.BIN in Fig. 4).

Based on the 20 streamflow records, we were able to group the different RAMs by the derived recession characteristics. Lower envelopes consistently lead to significantly longer recession times (median 104 days) and larger storage depletions (median $61 \mathrm{~mm}$ ). While fitting by linear regression and binning resulted in shorter median recession times of 20 and 17 days and corresponding median storage depletions of 11 and $9 \mathrm{~mm}$, respectively, the relative ranking of these values was consistent for the different extraction methods constituting the RAMs. Interestingly, regression coefficients of 1 and almost 1 between both VOG.REG and BRU.REG as well as between VOG.BIN and BRU.BIN indicated that here the calculated recession characteristics are dominated more likely by the model-fitting method than by the extraction procedure. In contrast to these findings, we identified a ranking among extraction methods (BRU $>$ VOG $>$ KIR) when estimating storage depletion with lower envelope fittings (means of 100,82 and $55 \mathrm{~mm}$ for the 20 catchments).

\section{Discussion}

\subsection{Range of recession characteristics}

The RAMs used in this study were all applicable to all streamflow records, and the derived ranges of intercept and slope are in the range of literature values and can be interpreted with respect to both storage-outflow behavior and catchment characteristics. Brutsaert and Nieber (1977) stated that values of $b$ from 1 for late recession segments (long-time behavior) to 3 for early stages of recession (short-time behavior) are in a physically reasonable range. They identified decreasing slope $b$ in power-law storage-outflow relationships as a function of continuous drawdown, whereas Rupp and Selker (2006b) summarized that the range of slope $b$ may be used for aquifer characterization since values ranging from 1 to 2 indicated sloping aquifers and from 1.5 to 2 horizontal aquifers. If we consider the upper and lower $10 \%$ of calculated values to be outliers, in this study slope $b$ ranged from 1.1 to 2.1 with an average of 1.55 . Other studies have found comparable ranges of slope $b$ for different purposes, e.g. between 1 and 1.6 (Palmroth et al., 2010), approximately 2 (Biswal and Marani, 2010; Shaw and Riha, 2012) or even higher than 2 (Szilagyi et al., 2007). In fact individual recession events often have larger slopes $b$, but those are concealed in recession plots which contain all recession events (Rupp et al., 2009; Biswal and Marani, 2010; Shaw and Riha, 2012). The resulting reduction of slope of fitted models compared to individual events' recession slopes is a limitation of the presented RAMs based on recession plots. 
Table 2. Spearman's rank correlation coefficient $(\rho)$ for recession times $T_{\mathrm{R}}$ (above diagonal) and storage depletions $S_{\mathrm{R}}$ (below diagonal) calculated for pairs of all RAMs.

\begin{tabular}{|c|c|c|c|c|c|c|c|c|c|}
\hline \multicolumn{10}{|c|}{ Recession Time $T_{\mathrm{R}}$} \\
\hline \multirow{9}{*}{ 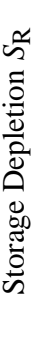 } & VOG.LE & 0.77 & 0.66 & 0.80 & 0.74 & 0.58 & 0.63 & 0.31 & 0.52 \\
\hline & 0.83 & VOG.REG & 0.91 & 0.70 & 0.89 & 0.73 & 0.64 & 0.63 & 0.53 \\
\hline & 0.70 & 0.92 & VOG.BIN & 0.61 & 0.84 & 0.80 & 0.62 & 0.73 & 0.54 \\
\hline & 0.83 & 0.67 & 0.57 & BRU.LE & 0.83 & 0.62 & 0.66 & 0.41 & 0.71 \\
\hline & 0.80 & 0.73 & 0.66 & 0.92 & BRU.REG & 0.86 & 0.76 & 0.69 & 0.65 \\
\hline & 0.79 & 0.81 & 0.78 & 0.82 & 0.89 & BRU.BIN & 0.73 & 0.70 & 0.55 \\
\hline & 0.72 & 0.86 & 0.90 & 0.71 & 0.79 & 0.91 & KIR.LE & 0.69 & 0.62 \\
\hline & 0.66 & 0.84 & 0.87 & 0.70 & 0.79 & 0.91 & 0.96 & KIR.REG & 0.58 \\
\hline & 0.62 & 0.78 & 0.82 & 0.74 & 0.79 & 0.84 & 0.89 & 0.91 & KIR.BIN \\
\hline
\end{tabular}

Similar to the slopes, the derived intercepts are in the range of literature values (e.g. Szilagyi et al., 2007; Palmroth et al., 2010; Shaw and Riha, 2012). Generally, all intercepts have different units that are a function of slopes $b$, which hampers a direct interpretation of intercept patterns. Nevertheless, a catchment with the same value of slope $b$ but a higher value of intercept $a$ indicates a larger initial storage volume. However, we have shown that the pattern of the derived recession characteristics (recession times and storage depletion) among the RAMs is linked more closely with the pattern of intercepts than with the distribution of slopes (Fig. 3). Small intercepts lead to longer recession times and larger storage depletions (e.g. RAMs with model fitting by lower envelope), whereas shorter recession times and smaller storage depletions coincide with larger intercepts (e.g. RAMs with model fitting by binning). Apart from these patterns the distribution of fitted intercepts $a$ and slopes $b$ lead to a wide range of recession times and storage depletions. The interquartile ranges of all calculated storage depletion and recession time values are higher than $90 \mathrm{~mm}$ and 70 days, respectively. The variation of these recession characteristics over two orders of magnitude can be seen as an estimation of RAMs' inconsistency.

\subsection{Roles of extraction procedure and parameterization method}

Both the extraction procedure and the model-fitting method influence the parameterization of a storage-outflow relationship in a particular way. To elucidate these specific biases, we investigated the inherent effects that different extraction procedures and fitted models have. The ratio of analyzed streamflow data to total time-period length differs notably among the three recession extraction procedures: $32 \%$ (Kirchner), $13 \%$ (Vogel) and 7\% (Brutsaert). The smaller amount of data within Vogel's and Brutsaert's procedures is mainly caused by the required minimum length of recession segments and the strict elimination of non-recession parts. Furthermore, both procedures exclude 3-4 days of early recession stages; thus recessions have to last at least 4-5 days to be considered. However, RAMs with Kirchner's extraction procedure take early stages of recession into account and consequently lead to shorter recession times and smaller storage depletions no matter which model-fitting method is used.

Parameters estimated by linear regression and binning show that the upper parts of recession plots (with higher $-\mathrm{d} Q / \mathrm{d} t$ from early recession stages) influence the fitted parameters. Brutsaert and Lopez (1998) have shown that these upper parts are shaped by early stages of recession and thus are sensitive to excluded initial recession parts (1-6 days). Moreover, the authors derived different mean slopes with different regression techniques for 22 catchments and have demonstrated that different fitting approaches lead to considerable biases in estimated values of slope $b$. However, these authors discussed whether slope $b$ can be a function of the removed fraction ( $0-80 \%)$ of early recessions and found lower values for $b$ and more scatter with an increasing removed fraction. Zecharias and Brutsaert (1988a) concluded that an upper envelope is sensitive to length of eliminated early stage, because additionally excluded two and five days reduced the fitted slopes by $30 \%$ and $55 \%$, respectively. In light of these outcomes we assume that for all fitted models a smaller slope $b$ generally leads to a higher intercept $a$ and hence to larger storage depletion. Accordingly, the average calculated storage depletion for Vogel's and Brutsaert's RAM was $16 \mathrm{~mm}$ and $7 \mathrm{~mm}$ for Kirchner's RAM using linear regression fitting. In other words, the decrease of storage depletion by more than $50 \%$ can be attributed to approximately 3-4 days of early stage recession, which is neither considered by Vogel's nor Brutsaert's extraction method. Furthermore, Zecharias and Brutsaert (1988a) suggested that although early stages were eliminated various short-time effects like storm flow from the farthest parts of a catchment can contribute to the downstream outlet as a lagged signal, thereby distorting the late-time storage-outflow behavior.

The influence of the model-fitting method on the intercept $a$ is pronounced with generally higher values for linear regression and binning, because the regression line is shifted upwards compared to the lower envelope fit. Consequently, RAMs with linear regressions represent more 
averaged storage-outflow relationships, recession times and storage depletions, which are notably more influenced by the wider scatter of recession plots than lower envelopes. A very selective extraction method like Brutsaert's leads to very specific recession plots and thus further focuses the storageoutflow model parameterization, e.g. by excluding the early stage of a recession. Similarly, a weighted linear regression like Kirchner's through a catchment-specific amount of bins can also focus parameter estimation, e.g. by weighting smaller $-\mathrm{d} Q / \mathrm{d} t$ values and thus reducing influence of higher $-\mathrm{d} Q / \mathrm{d} t$ values, which in turn could represent early stages of recession. The highest Spearman's rank correlations among the RAMs based on Kirchner's extraction procedure suggest that the estimation of relative recession characteristics for a set of catchments depends more on the amount of data in recession plots than on the choice of a fitting model.

Biases in model fitting are manifold. For instance, lower envelopes can be affected by the precision of streamflow measurements (Rupp and Selker, 2006a). Multiples of the lowest detectable $-\mathrm{d} Q / \mathrm{d} t$ value sometimes produce a horizontal scatter in recession plots which influence the parameterization of the storage-outflow model. In Fig. 1 we illustrated that a horizontal scatter for small $-\mathrm{d} Q / \mathrm{d} t$ in recession plots can be detected most frequently by using Kirchner's and rarely by Vogel's extraction procedure. Vogel's moving average seems to reduce this scatter, whereas Kirchner's extraction method leads to a more extensive scatter caused by considering all negative $\mathrm{d} Q / \mathrm{d} t$. To reduce the influence of scatter on lower envelopes, Rupp and Selker (2006a) suggested to enlarging the time-step to calculate $-\mathrm{d} Q / \mathrm{d} t$ and averaging $Q$ until the decline in streamflow is higher than measurement precision of streamflow. This scatter reduction in recession plots might improve model fit and has been applied in a number of studies (e.g. Clark et al., 2009; Palmroth et al., 2010; Ajami et al., 2011; Staudinger et al., 2011).

However, fitting by lower envelope is not only sensitive to the precision of streamflow measurements but also might be biased by the proportion of analyzed streamflow data in the recession plots. The absolute number of recession data points that remained under the lower envelope differs among the RAMs with a maximum of 99 for the Brutsaert extraction method (minimum 7, average 48) based on all catchments (each with a 38-yr daily streamflow record). In other words, a very selective extraction procedure like Brutsaert's can lead to recession plots shaped by only $1 \%$ of all streamflow data and lower envelopes with around $0.35 \%$ of all streamflow data below them. As these remaining data points may be extracted from only a few recession events, we see issues of balancing selectivity of an extraction procedure against the reliability of derived storage-outflow relationships and insufficient comparability based on this method-specific selectivity. Other studies have fitted lower envelopes with $3-10 \%$ of data points, depending on data availability or to test the sensitivity of lower envelopes related to derived intercepts (Troch et al., 1993; Szilagyi and Parlange, 1998; Malvicini et al., 2005).

Finally, the relative roles of extraction procedure and model fitting can be elucidated with an analysis of Kirchner's RAMs. Kirchner (2009) argued that the influence of highly uncertain points has to be reduced to find representative values for certain ranges of $-\mathrm{d} Q / \mathrm{d} t$ and $Q$. Subsequently, bins with smaller standard errors gain more weight, which typically can be found for lower values of $-\mathrm{d} Q / \mathrm{d} t$. In other words, lower bins (with smaller $Q$ values) have more influence on regression than bins with higher $Q$ values. Nevertheless one might argue that streamflow measurement is less precise for lower $Q$ values, while early stages of recession with higher $Q$ do not reflect undistorted storage depletion. The faster drainage characterized by the RAMs that used binning has two reasons: Kirchner's extraction procedure considers the early stages of recession and the weighted linear regression (through the binning) leads more often to reduced slopes $b$, which in turn resulted in higher intercepts $a$.

\subsection{The effect of different RAMs to distinguish catchments' recession characteristics}

Variations in the derived parameters $a$ and $b$ will influence common applications of RAMs that rely on characteristic recession behavior of catchments. The results of recession analysis are often related directly to physical characteristics such as drainable porosity, hydraulic conductivity, aquifer thickness and other basin-wide hydraulic or geomorphological parameters such as drainage area or stream length (Brutsaert and Nieber, 1977; Zecharias and Brutsaert, 1988b; Parlange et al., 2001; Dewandel et al., 2003). Beyond that, RAMs are often used to estimate recession behavior over different scales (e.g. hillslopes, catchment size) (Clark et al., 2009; Wang, 2011) or to characterize storage capacity (Sayama et al., 2011) or recession timescales (Aksoy and Wittenberg, 2011; Brutsaert, 2008; Krakauer and Temimi, 2011). In these applications, the choice of RAM will directly influence the estimated properties of water availability. Our results suggest that in such applications the choice of RAM either needs to be consciously justified by the specific bias caused by extraction and fitting procedure, or alternatively a multiple-RAM approach may be appropriate to quantify a range of potential characteristics.

Intercepts as parameters of recession models have been related to catchment characteristics such as drainage density or geomorphic properties for regionalization purposes and estimation in ungauged catchments (Vogel and Kroll, 1992; Tague and Grant, 2004; Brutsaert and Sugita, 2008; Aksoy and Wittenberg, 2011). In this study we found that the derived intercepts vary by a factor of 20 , but with the addition that this variation may be smaller because intercept $a$ depends on slope $b$. Fixed slopes of approximately $b=1.5$ have been suggested to calibrate parameter $a$ and to regionalize non-linear storage-outflow (Wittenberg, 1999), 
but one should note that for the RAMs in this study the slopes differ notably between 1 and 2 . Some studies have linked slopes $b$ to the spatial scale and found that a linear relationship for storage-outflow $(b=1)$ was suitable for hillslopes but turned more and more into non-linear behavior $(b>1)$ with increasing catchment scale and catchment heterogeneity (Clark et al., 2009; Harman et al., 2009). We found no systematic pattern between slopes $b$ and catchment area (not shown), although area often has been identified as a catchment characteristic for regional low-flow regression models (Eng and Milly, 2007). This may be due to the non-characteristic results of a RAM caused by aquifer heterogeneity (Rupp and Selker, 2005; Harman et al., 2009) or the unknown number of aquifers that contribute recession streamflow to each catchment (Ajami et al., 2011).

Recession characteristics have also been used for catchment classification (Wagener et al., 2007; Carrillo et al., 2011; Sawicz et al., 2011), especially with a view to a heuristic understanding of the interaction between climate (in terms of available precipitation and changing evapotranspiration rates), transferable catchment characteristics and the corresponding streamflow dynamics. While absolute values of the recession characteristics may not be so important for such applications, the analysis of Spearman's rank correlation coefficient and the regression coefficient between characteristics obtained with different RAMs has elucidated differences in the relative values. Interestingly the catchment ranking among the original recession analysis methods (VOG.REG, BRU.LE, KIR.BIN) is not consistent. Apart from the original RAMs, however, in the bundle of methods there is more general consistency in the ranking of recession time and storage depletion among catchments than in the values of the calculated recession characteristics (e.g. median storage depletion for each of the nine RAMs leads to an maximum difference between Vogel's lower envelope and Kirchner's binning of $67 \mathrm{~mm}$ and to a moderate Spearman's rank correlation coefficient). Whereas it is difficult to identify the source of bias, ranking is more consistent and differences are somewhat smaller among RAMs with the same extraction procedure (see Sect. 5.2). Nevertheless, these inconsistencies have the potential to hamper a robust classification and its interpretation, as every statistical classification is based on relative similarities and differences. The inconsistency found among the methods presents a limitation for regionalization, because it has shown a wide range of recession characteristics calculated for one specific catchment with particular physical characteristics.

Finally, implications exist for application of low-flow forecasting based on recession characteristics. For this task the application of multiple parameter sets (derived from the use of different RAMs) as an ensemble forecast is a feasible option, although the spread of the members will be very large (Stoelzle et al., 2012) and the prediction may potentially become non-specific to the catchment.

\section{Conclusions}

We tested the effect of different recession analysis methods to distinguish recession characteristics in a regional set of streamflow records caused by particular catchment characteristics. The results of this study suggest four main conclusions.

The bundle of established RAMs produces a high variability of recession parameter values and derived recession characteristics. Systematic variations in particular regarding the absolute values exist among the methods, making it difficult to distinguish recession characteristics among the catchments. While some RAMs rank the catchments relatively consistently with respect to their derived recession characteristics, the three original RAMs rank them differently.

The roles of recession extraction procedures and fitting method for parameterization of storage-outflow models are complex, and the interaction of the recession analysis components has various effects on the derived recession characteristics. We suggest paying attention to the extraction of different stages of recession - but also to the physical meaning of different fitting methods (e.g. lower envelopes representing slowly receding streamflow recessions), as they focus on a specific storage-outflow relationship. Furthermore, reconsidering single recession events or a master recession may be a possibility to validate parameterization of RAM derived by recession plots (Shaw and Riha, 2012).

We suggest that the limited comparability of recession characteristics derived with different RAMs highlights the distinctiveness of individual analysis methods. Unless a particularly distinctive method is consciously wanted in an application, we thus recommend an approach based on a combination of RAMs and their properties to investigate streamflow recession characteristics whenever the application allows the use of a combination of multiple solutions.

The majority of the tested RAMs are too specific to reflect all catchment characteristics that control recession behavior. Possible specific catchment characteristics are blurred by the variability of parameters from different RAMs. The inconsistency among methods may hence be too large for the regionalization of streamflow recession behavior or for catchment classification based on the compared RAMs.

Acknowledgements. The first author was supported by scholarship funds from the State Graduate Funding Program of BadenWürttemberg (LGFG). Streamflow data were provided by the Environment Agency of the German state of Baden-Württemberg (LUBW). The Open Access Publication Fund of the German Research Foundation (DFG) covered the publication costs.

Edited by: C. Harman 


\section{References}

Ajami, H., Troch, P. A., Maddock III, T., Meixner, T., and Eastoe, C.: Quantifying mountain block recharge by means of catchment-scale storage-discharge relationships, Water Resour. Res., 47, W04504, doi:10.1029/2010WR009598, 2011.

Aksoy, H. and Wittenberg, H.: Nonlinear baseflow recession analysis in watersheds with intermittent streamflow, Hydrol. Sci. J., 56, 226-237, doi:10.1080/02626667.2011.553614, 2011.

Anderson, M. and Burt, T.: Interpretation of recession flow, J. Hydrol., 46, 89-101, doi:10.1016/0022-1694(80)90037-2, 1980.

Biswal, B. and Marani, M.: Geomorphological origin of recession curves, Geophys. Res. Lett., 37, L24403, doi:10.1029/2010GL045415, 2010.

Brutsaert, W.: Long-term groundwater storage trends estimated from streamflow records: Climatic perspective, Water Resour. Res., 44, W02409, doi:10.1029/2007WR006518, 2008.

Brutsaert, W. and Lopez, J. P.: Basin-scale geohydrologic drought flow features of riparian aquifers in the southern Great Plains, Water Resour. Res., 34, 233-240, 1998.

Brutsaert, W. and Nieber, J. L.: Regionalized drought flow hydrographs from a mature glaciated plateau, Water Resour. Res., 13, 637-643, 1977.

Brutsaert, W. and Sugita, M.: Is Mongolia's groundwater increasing or decreasing? The case of the Kherlen River basin, Hydrol. Sci. J., 53 1221-1229, 2008.

Carrillo, G., Troch, P. A., Sivapalan, M., Wagener, T., Harman, C., and Sawicz, K.: Catchment classification: hydrological analysis of catchment behavior through process-based modeling along a climate gradient, Hydrol. Earth Syst. Sci., 15, 3411-3430, doi:10.5194/hess-15-3411-2011, 2011.

Clark, M. P., Rupp, D. E., Woods, R. A., Tromp-van Meerveld, H. J., Peters, N. E., and Freer, J. E.: Consistency between hydrological models and field observations: linking processes at the hillslope scale to hydrological responses at the watershed scale, Hydrol. Process., 23, 311-319, doi:10.1002/hyp.7154, 2009.

Dewandel, B., Lachassagne, P., Bakalowicz, M., Weng, P., and Al-Malki, A.: Evaluation of aquifer thickness by analysing recession hydrographs. Application to the Oman ophiolite hardrock aquifer, J. Hydrol., 274, 248-269, doi:10.1016/S00221694(02)00418-3, 2003.

Ding, J. Y.: Discussion of "Inflow hydrographs from large unconfined aquifers" by Ibrahim, H. A. and Brutsaert, W., J. Irrig. Drain. Div. Am. Soc. Civ. Eng., 92, 104-107, 1966.

Ding, J. Y.: Variable unit hydrograph, J. Hydrol., 22, 53-69, doi:10.1016/0022-1694(74)90095-X, 1974.

Eng, K. and Milly, P. C. D.: Relating low-flow characteristics to the base flow recession time constant at partial record stream gauges, Water Resour. Res., 43, W01201, doi:10.1029/2006WR005293, 2007.

Federer, C.: Forest transpiration greatly speeds streamflow recession, Water Resour. Res., 9, 1599-1604, 1973.

Gottschalk, L., Tallaksen, L. M.. and Perzyna, G.: Derivation of low flow distribution functions using recession curves, J. Hydrol., 194, 239-262, 1997.

Halford, K. J. and Mayer, G. C.: Problems Associated with Estimating Ground Water Discharge and Recharge from Stream-Discharge Records, Ground Water, 38, 331-342, doi:10.1111/j.1745-6584.2000.tb00218.x, 2000.
Hall, F. R.: Base-flow recessions - a review, Water Resour. Res., 4, 973-983, 1968.

Harman, C. J., Sivapalan, M., and Kumar, P.: Power law catchment-scale recessions arising from heterogeneous linear small-scale dynamics, Water Resour. Res., 45, W09404, doi:10.1029/2008WR007392, 2009.

Kirchner, J. W.: Catchments as simple dynamical systems: Catchment characterization, rainfall-runoff modeling, and doing hydrology backward, Water Resour. Res., 45, W02429, doi:10.1029/2008WR006912, 2009.

Koenker, R. and Bassett Jr., G.: Regression quantiles, Econometrica, 46, 33-50, 1978.

Krakauer, N. Y. and Temimi, M.: Stream recession curves and storage variability in small watersheds, Hydrol. Earth Syst. Sci., 15, 2377-2389, doi:10.5194/hess-15-2377-2011, 2011.

Lyon, S. W., Destouni, G., Giesler, R., Humborg, C., Mörth, M., Seibert, J., Karlsson, J., and Troch, P. A.: Estimation of permafrost thawing rates in a sub-arctic catchment using recession flow analysis, Hydrol. Earth Syst. Sci., 13, 595-604, doi:10.5194/hess-13-595-2009, 2009.

Malvicini, C. F., Steenhuis, T. S., Walter, M. T., Parlange, J. Y., and Walter, M. F.: Evaluation of spring flow in the uplands of Matalom, Leyte, Philippines, Adv. Water. Resour., 28, 1083-1090, doi:10.1016/j.advwatres.2004.12.006, 2005.

Mendoza, G. F., Steenhuis, T. S., Walter, M. T., and Parlange, J. Y.: Estimating basin-wide hydraulic parameters of a semi-arid mountainous watershed by recession-flow analysis, J. Hydrol., 279, 57-69, doi:10.1016/S0022-1694(03)00174-4, 2003.

Palmroth, S., Katul, G. G., Hui, D., McCarthy, H. R., Jackson, R. B., and Oren, R.: Estimation of long-term basin scale evapotranspiration from streamflow time series, Water Resour. Res., 46, W10512, doi:10.1029/2009WR008838, 2010.

Parlange, J., Stagnitti, F., Heilig, A., Szilagyi, J., Parlange, M., Steenhuis, T., Hogarth, W., Barry, D., and Li, L.: Sudden drawdown and drainage of a horizontal aquifer, Water Resour. Res., 37, 2097-2101, 2001.

Peña-Arancibia, J. L., van Dijk, A. I. J. M., Mulligan, M., and Bruijnzeel, L. A.: The role of climatic and terrain attributes in estimating baseflow recession in tropical catchments, Hydrol. Earth Syst. Sci., 14, 2193-2205, doi:10.5194/hess-14-21932010, 2010.

Price, K.: Effects of watershed topography, soils, land use, and climate on baseflow hydrology in humid regions: A review, Prog. Phys. Geogr., 35, 465-492, doi:10.1177/0309133311402714, 2011.

Rupp, D. E. and Selker, J. S.: Drainage of a horizontal Boussinesq aquifer with a power law hydraulic conductivity profile, Water Resour. Res., 41, W11422, doi:10.1029/2005WR004241, 2005.

Rupp, D. E. and Selker, J. S.: Information, artifacts, and noise in $\mathrm{d} Q / \mathrm{d} t-Q$ recession analysis, Adv. Water. Resour., 29, 154-160, doi:10.1016/j.advwatres.2005.03.019, 2006a.

Rupp, D. E. and Selker, J. S.: On the use of the Boussinesq equation for interpreting recession hydrographs from sloping aquifers, Water Resour. Res., 42, W12421, doi:10.1029/2006WR005080, 2006b.

Rupp, D. E., Schmidt, J., Woods, R. A., and Bidwell, V. J.: Analytical assessment and parameter estimation of a lowdimensional groundwater model, J. Hydrol., 377, 143-154, doi:10.1016/j.jhydrol.2009.08.018, 2009. 
Sawicz, K., Wagener, T., Sivapalan, M., Troch, P. A., and Carrillo, G.: Catchment classification: empirical analysis of hydrologic similarity based on catchment function in the eastern USA, Hydrol. Earth Syst. Sci., 15, 2895-2911, doi:10.5194/hess-15-28952011, 2011.

Sayama, T., McDonnell, J. J., Dhakal, A., and Sullivan, K.: How much water can a watershed store?, edited by: Tetzlaff, D., Carey, S., and McNamara, J., Hydrol. Process., 25, 3899-3908, doi:10.1002/hyp.8288, 2011.

Schäfer, K., Oren, R., and Tenhunen, J.: The effect of tree height on crown level stomatal conductance, Plant Cell Environ., 23, 365375,2000

Shaw, S. B. and Riha, S. J.: Examining individual recession events instead of a data cloud: Using a modified interpretation of $\mathrm{d} Q / \mathrm{d} t-Q$ streamflow recession in glaciated watersheds to better inform models of low flow, J. Hydrol., 434-435, 46-54, doi:10.1016/j.jhydrol.2012.02.034, 2012.

Singh, K. P. and Stall, J. B.: Derivation of base flow recession curves and parameters, Water Resour. Res., 7, 292-303, 1971.

Smakhtin, V.: Low flow hydrology: a review, J. Hydrol., 240, 147186, doi:10.1016/S0022-1694(00)00340-1, 2001.

Staudinger, M., Stahl, K., Seibert, J., Clark, M. P., and Tallaksen, L. M.: Comparison of hydrological model structures based on recession and low flow simulations, Hydrol. Earth Syst. Sci., 15, 3447-3459, doi:10.5194/hess-15-3447-2011, 2011.

Stoelzle, M., Stahl, K., and Weiler, M.: As simple as possible? Drought recognition based on streamflow recession, 10th International Conference on Hydroinformatics, Hamburg, 1-8, 2012.

Szilagyi, J. and Parlange, M. B.: Baseflow separation based on analytical solutions of the Boussinesq equation, J. Hydrol., 204, 251-260, 1998

Szilagyi, J., Gribovszki, Z., and Kalicz, P.: Estimation of catchmentscale evapotranspiration from baseflow recession data: Numerical model and practical application results, J. Hydrol., 336, 206217, doi:10.1016/j.jhydrol.2007.01.004, 2007.

Tague, C. and Grant, G.: A geological framework for interpreting the low-flow regimes of Cascade streams, Willamette River Basin, Oregon, Water Resour. Res., 40, W04303, doi:10.1029/2003WR002629, 2004.

Tallaksen, L.: A review of baseflow recession analysis, J. Hydrol., 165, 349-370, 1995.
Teuling, A. J., Lehner, I., Kirchner, J. W., and Seneviratne, S. I.: Catchments as simple dynamical systems: Experience from a Swiss prealpine catchment, Water Resour. Res., 46, W10502, doi:10.1029/2009WR008777, 2010.

Troch, P., De Troch, F., and Brutsaert, W.: Effective Water-Table Depth to Describe Initial Conditions Prior to Storm Rainfall in Humid Regions, Water Resour. Res., 29, 427-434, 1993.

van Dijk, A. I. J. M.: Climate and terrain factors explaining streamflow response and recession in Australian catchments, Hydrol. Earth Syst. Sci., 14, 159-169, doi:10.5194/hess-14-159-2010, 2010.

Vogel, R. and Kroll, C.: Regional geohydrologic-geomorphic relationships for the estimation of low-flow statistics, Water Resour. Res., 28, 2451-2458, 1992.

Wagener, T., Sivapalan, M., Troch, P., and Woods, R.: Catchment Classification and Hydrologic Similarity, Geogr. Compass, 1, 901-931, doi:10.1111/j.1749-8198.2007.00039.x, 2007.

Wang, D.: On the base flow recession at the Panola mountain research watershed, Georgia, United States, Water Resour. Res., 47, W03527, doi:10.1029/2010WR009910, 2011.

Wang, D. and Cai, X.: Detecting human interferences to low flows through base flow recession analysis, Water Resour. Res., 45, W07426, doi:10.1029/2009WR007819, 2009.

Wang, D. and Cai, X.: Comparative study of climate and human impacts on seasonal baseflow in urban and agricultural watersheds, Geophys. Res. Lett., 37, L06406, doi:10.1029/2009GL041879, 2010.

Wittenberg, H.: Baseflow recession and recharge as nonlinear storage processes, Hydrol. Process., 13, 715-726, 1999.

Wittenberg, H. and Sivapalan, M.: Watershed groundwater balance estimation using streamflow recession analysis and baseflow separation, J. Hydrol., 219, 20-33, doi:10.1016/S00221694(99)00040-2, 1999.

Zecharias, Y. B. and Brutsaert, W.: Recession characteristics of groundwater outflow and base flow from mountainous watersheds, Water Resour. Res., 24, 1651-1658, doi:10.1029/WR024i010p01651, 1988a.

Zecharias, Y. B. and Brutsaert, W.: The influence of basin morphology on groundwater outflow, Water Resour. Res., 24, 1645-1650, 1988 b. 